\title{
AMBIENTES BIOFÍSICOS URBANOS ${ }^{1}$
}

\author{
MARGARIDA QuEIRÓs ${ }^{2}$
}

Os geógrafos australianos têm publicado os resultados de investigações efectuadas no seu país pensando na necessidade de suprir as carências dos alunos universitários através da edição de pequenas obras, a baixos custos e, ao mesmo tempo, procurando diminuir as falhas entre os resultados de investigações sobre a Austrália e a sua divulgação mais alargada. O Instituto de Geógrafos Australianos iniciou a publicação da série Meridian: Australian Geographical Perspectives no sentido de preencher estas lacunas.

O sétimo livro da série, Urban Biophysical Environments, reúne três geógrafos com preocupações, nas áreas da investigação e do ensino, acerca do ambiente biofísico urbano nas cidades australianas. Com esta publicação, os professores Bridgman, Warner e Dodson ${ }^{3}$ identificam impactes negativos da actividade e concentração humana no ambiente urbano - atmosféricos, hidrológicos e biológicos - com o objectivo de promover soluções para a sua adequada gestão.

As cidades australianas são relativamente recentes face a outras áreas urbanas e estão a crescer muito rapidamente. Na Austrália, o povoamento concentra-se no litoral e as cidades albergam $80 \%$ da população do país, em contraste com o interior, virtualmente desabitado. Apesar da sua relativa juventude, as cidades australianas exibem muitas das características e problemas de qualquer cidade no mundo, ao mesmo tempo que colocam um conjunto único de dificuldades que exigem soluções individualizadas.

O processo de urbanização desenvolveu-se de uma forma diferenciada da Europa, não havendo uma forte tradição das populações rurais ligadas à agricultura, sendo a população maioritariamente urbana. A urbanização foi iniciada por condenados e seus guardas que, junto de portos de abrigo, formaram as maiores cidades. As estruturas do governo colonial ali se localizaram, tornando-se, mais tarde, as capitais regionais. O mais interessante e pouco habitual nestas aglomerações resulta do facto de elas se terem desenvolvido após a revolução industrial na Europa. Assim, muitas cidades são criações do século XIX, mantiveram-se pequenas e nelas rapidamente se instalou a indús-

1 Bridgman, H.; Warner, R.; Dodson, J. (2000) - Urban Biophysical Environments. Oxford University Press, Melbourne: 152p.

2 Prof. ${ }^{a}$ Auxiliar do Departamento de Geografia da FLUL e Investigadora do Centro de Estudos Geográficos da Universidade de Lisboa. E-mail: margaridaq@ceg.ul.pt.

3 Howard Bridgman, Robin Warner e John Dodson são Professores de Geografia da Universidade de Newcastle, da Universidade de Sydney e da Universidade de Western Austrália, respectivamente. 
tria ligeira, enquanto a indústria pesada se desenvolveu lentamente e ficou associada a cidades novas, como Newcastle e Wollongong. Tratam-se de cidades planeadas para as quais se adoptaram padrões espaciais ortogonais (Melbourne, Adelaide e Perth), enquanto as cidades portuárias (Sydney) e estuarinas (Brisbane e Hobart) apresentam um padrão mais orgânico. Quando o caminho-de-ferro chegou, as estações foram construídas junto dos centros de negócios (CBD) e os sistemas urbanos de transporte facilitaram as deslocações diárias durante os finais do século XIX e ao longo de todo o século XX.

Actualmente, as cidades mais importantes são Sydney, Melbourne, Brisbane, Adelaide, Perth e Hobart. Cerca de $63 \%$ dos australianos vive nas duas maiores cidades (Sydney e Melbourne) e outros 22\% residem em cidades mais pequenas. Sydney tem actualmente 3,6 milhões de habitantes (em 1851, tinha apenas uma população de 51 mil habitantes) e Melbourne 3,1 milhões. A Austrália é assim um dos três países mais urbanizados do mundo.

Apesar do ambiente físico urbano da Austrália corresponder apenas a 0,5\% da área total continental, alberga cerca de $85 \%$ da sua população. Os estilos de vida urbanos são aspectos essenciais no quotidiano dos australianos e as cidades capitais são centros fundamentais do crescimento económico. Esta imensa aglomeração populacional cria condições benéficas ao desenvolvimento mas implica fortes pressões e impactes ambientais negativos.

Os efeitos do ar, solos, água e vegetação degradados ou poluídos em áreas urbanas são apresentados e discutidos neste livro, bem como os processos e estratégias para a sua gestão, o papel das instituições públicas, das organizações não governamentais e a importância do pensamento estratégico sobre o futuro das cidades. Se bem que muitos planos de gestão ambiental estejam em curso nas cidades australianas, os autores apelam para a urgência em pensar o controlo sobre o ambiente físico urbano cujos problemas não param de aumentar, criando dificuldades crescentes às populações urbanas no futuro.

O livro estrutura-se em sete pequenos capítulos: 1. introdução: o processo de urbanização na Austrália, as estruturas físicas e formas urbanas e as cidades capitais; 2. o impacte da urbanização no clima; 3. qualidade do ar e saúde no ambiente urbano; 4. impactes da urbanização nos solos e na hidrologia; 5. os impactes adversos da urbanização dos solos e das águas nos humanos e ecologia; 6. os impactes da urbanização nos sistemas biológicos; 7. as áreas verdes urbanas e a qualidade de vida e 8. a gestão ambiental urbana e o futuro. Se o primeiro capítulo descreve o processo de urbanização e suas consequências na Austrália, bem como as semelhanças e diferenças entre as cidades principais, nos seguintes consideram-se os impactes da urbanização nos sistemas atmosféricos, geomorfológicos, hidrológicos e biológicos e os efeitos destes sistemas modificados nas populações urbanas. O capítulo final sintetiza toda a discussão anterior para equacionar futuros desenvolvimentos.

A abordagem multidisciplinar da publicação revela uma preocupação com o impacte das cidades australianas na atmosfera, clima, água, solo, flora e fauna e ecossistemas, evidenciando que o recente desenvolvimento urbano na Austrália tem impactes nos ambientes biofísicos envolventes, com efeitos negativos na saúde, bem-estar e estilos de vida dos residentes. Dando-nos a conhecer a estrutura do sistema urbano na Austrália, Urban Biophysical Environments procura também avaliar e emergência de problemas urbanos de um ponto de vista físico. É sem dúvida um objectivo deste livro apresentar, de uma forma didáctica, um conjunto de princípios e de conceitos implicados nos processos físicos e biológicos da urbanização e discutir como estes impactes afectam a qualidade de vida das populações nas cidades. 
Dado que a publicação em análise assume um leitor com poucos conhecimentos nestas áreas, torna-se um trabalho pedagógico e interessante para o público em geral, demonstrando que a geografia tem algo de distintivo a dizer sobre questões ambientais contemporâneas. Decerto um livro para estudantes, cujos tópicos seleccionados revelam assuntos importantes e actuais para os australianos e também para todos aqueles que estudam e se preocupam com a qualidade de vida nas cidades. 